
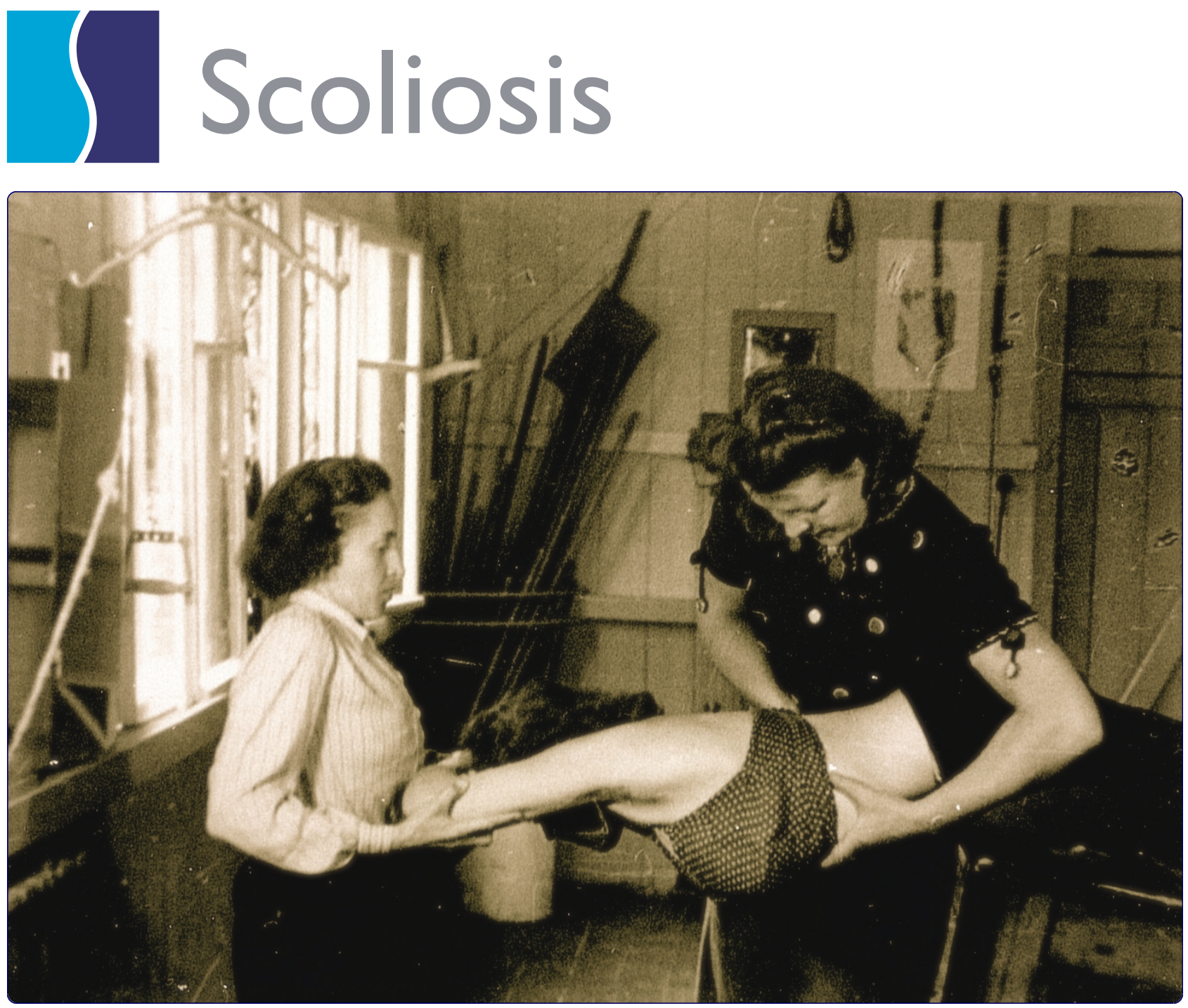

\title{
Spinal deformities rehabilitation - state of the art review
}

Weiss

C Biomed Central 


\title{
Spinal deformities rehabilitation - state of the art review
}

\author{
Hans-Rudolf Weiss
}

\begin{abstract}
Background: Medical rehabilitation aims at an improvement in function, capacity and participation. For the rehabilitation of spinal deformities, the goal is to maintain function and prevent secondary symptoms in the shortand long-term. In patients with scoliosis, predictable signs and symptoms include pain and reduced pulmonary function,

Materials and methods: A Pub Med review was completed in order to reveal substantial evidence for inpatient rehabilitation as performed in Germany. No evidence has been found in general to support claims for actual inpatient rehabilitation programmes as used today. Nevertheless, as there is some evidence that inpatient rehabilitation may be beneficial to patients with spinal deformities complicated by certain additional conditions, the body of evidence there is for conservative treatment of spinal deformities has been reviewed in order to allow suggestions for outpatient conservative treatment and inpatient rehabilitation.
\end{abstract}

Discussion: Today, for both children and adolescents, we are able to offer intensive rehabilitation programmes lasting three to five days, which enable the patients to acquire the skills necessary to prevent postures fostering scoliosis in everyday life without missing too much of school teaching subjects at home. The secondary functional impairments adult scoliosis patients might have, as in the opinion of the author, still today require the time of 3-4 weeks in the clinical in-patient setting. Time to address psychosocial as well as somatic limitations, namely chronic pains and cardiorespiratory malfunction is needed to preserve the patients working capability in the long-term.

Conclusion: Outpatient treatment/rehabilitation is sufficient for adolescents with spinal deformities. Inpatient rehabilitation is recommended for patients with spinal deformities and pain or severe restrictive ventilation disorder.

\section{Background}

Medical rehabilitation aims at an improvement in function, capacity and participation [1]. Outpatient and inpatient programmes are available worldwide for the rehabilitation of patients with impairments or disabilities in various medical fields. Particularly in Germany, there is a long history of inpatient rehabilitation for various diseases. The German Pension Insurance scheme has introduced a comprehensive practice guidelines programme for the development of process guidelines for inpatient rehabilitation. However, outcome studies in this field are very rare, which would justify the costs of such treatment. In the era of evidence based medicine, the usefulness, necessity and efficiency of inpatient

Correspondence: hr.weiss@skoliose-dr-weiss.com

Orthopedic Rehabilitation Services, D-55457 Gensingen, Alzeyerstr. 23, Germany rehabilitation has to be proven as does every other mode of treatment. For the German system of inpatient rehabilitation of chronic back pain, available evidence is not conclusive, due to a lack of randomised controlled studies. The prevailing design of observational cohort studies has severe limitations in proving a causal relationship between outcomes and intervention [2].

There are numerous papers providing evidence that outpatient rehabilitation is as effective as inpatient rehabilitation [3-10]. An outpatient cancer rehabilitation programme for instance, may be an effective alternative treatment to inpatient programmes for specific groups of patients [3].

There are no indications of poorer care quality in outpatient rehabilitation of orthopaedic patients, while economic analyses show better cost effectiveness in outpatient treatment by comparability of treatment, 
patients, and results [5]. The results of the latter study suggest that outpatient care, offered in the same quality as in the examined rehabilitation centres, is an alternative or complement to inpatient care at least for those patients, who can be treated in both the outpatient and inpatient setting [5]. Also different cardiac rehabilitation programmes (in- and outpatient) can be regarded as comparable concerning effectiveness and costs following rehabilitation [6].

\section{Limitations assumed in patients with spinal deformities}

Rehabilitation is the process of assisting someone to improve and recover lost function after an event, illness or injury that has caused functional limitations. Rehabilitation engineering is the application of engineering sciences to design, develop, adapt, test, evaluate, apply, and distribute technological solutions to problems confronted by individuals with disabilities [1]. The term 'rehabilitation' however, includes psychosocial issues as well as participation and psychological stress.

But how can we define rehabilitation in the context of spinal deformities? First we need to acknowledge the functional limitations in patients with spinal deformities. An overview is given in the SOSORT consensus paper on physical exercises [11]:

For treatment of all spinal deformities, the goal is to maintain function and prevent symptoms in the shortand long-term. In patients with scoliosis, as summarized below, predictable signs and symptoms including pain and reduced pulmonary function may begin early in life and may worsen with age. Some curvatures still present at skeletal maturity also continue to worsen throughout life. For children with scoliosis, therefore, optimal treatment goals include reversing curvature magnitude and/ or preventing curvature progression, pain, and pulmonary dysfunction over a lifetime.

\section{Pain}

Most clinical outcome surveys have revealed that, by early adulthood, the majority of scoliosis patients suffer from pain [12-26]. Only one large controlled survey has been carried out to date [27]. In that study, 1178 young adults, interviewed 10 years after diagnosis in adolescence, reported a significantly higher incidence of pain than 1217 control subjects. Of the scoliosis patients reporting pain, 23\% (147/650) described it as 'horrible, excruciating, distressing' compared with 1\% (6/416) of the control subjects who reported pain. Similar results were reported at $>44$ year followup [28]. Of a subset of 69 patients treated in adolescence (from an original population of 444), twice as many scoliosis patients (77\% vs 35\%) suffered from pain compared with a population of adults of comparable age (> 55 years). Incidence of chronic pain was almost three fold higher in the scoliosis patients (61\%) compared with the controls without scoliosis (22\%). This is despite the fact that the 'control" popoulation was selected from hospital clinics, nursing homes, and senior citizens' centres where incidence of disability is exceptionally high $[29,30]$. How scoliosis causes pain is not clear, but the magnitude of pain in adult scoliosis patients recently has been found to be inversely proportional to curvature flexibility [31]. Related factors linked with pain include regional balance, instability and pathological mechanical loads on spinal elements [32].

\section{Pulmonary dysfunction}

Thoracic scoliosis in children results in characteristic signs of pulmonary dysfunction including reduced vital capacity (VC) and impaired exercise capacity (EC) [33-40]. Because the mechanism for impaired function is reduced, mobility of the chest wall deteriorates with age, pulmonary function deteriorates according to curvature magnitude even when the curvature itself does not progress [41-46]. In severe cases death occurs by respiratory failure [42-46]. The effects of reduced pulmonary function in patients with mild to moderate scoliosis are not known and have been dismissed as insignificant [e.g., $[47,48]]$. Recent studies, however, have shown that VC and EC characteristic of patients with mild to moderate scoliosis $(<85 \%$ predicted) are more reliable predictors of increased mortality than diabetes, high blood pressure, and heart disease [47-51]. Patient-described pulmonary symptoms, in general, are not a reliable indicator because patients are usually unaware of their limitations even when documented signs are severe and respiratory failure is imminent [40-44,51-55].

\section{Progression}

Once a flexible spinal curvature evolves into a spinal deformity, a 'vicious cycle' is initiated in which continuous asymmetric loading of the spinal elements fosters continued progression [55-57]. Only a few small surveys have examined the epidemiology of progression and insufficient information is available to reliably predict outcome for any given patient $[58,59]$. In general, the danger for dramatic progression is highest during periods of rapid growth, but most cases continue to progress throughout life [59-61]. Some individuals with similar curves exhibit marked progression after skeletal maturity while others are relatively stable [52]. The bases for such differences are unknown, though some have suggested that the likelihood of progression is greater the more rigid the curvature [62].

Taking into account the literature as listed above, scoliosis seems to coincide with a very bad prognosis if left untreated. On the other hand, reviews exist, which enlighten the prognosis of Adolescent Idiopathic Scoliosis (AIS) in another way $[28,63]$. Within these studies it has been shown that AIS is more benign than 'scoliosis' 
as investigated in other studies without differentiation of its etiology $[28,63]$.

As AIS is the most common form of scoliosis, it seems appropriate to distinguish between this diagnosis and scoliosis of other origin.

Therefore, it seems reasonable to have a closer look at the early reviews by Weinstein [28] and a more recent review by Asher and Burton [63], clearly showing that the prognosis of AIS is not as bad as of scoliosis of other origin may be $[28,63]$.

If we take into account the relative benign prognosis of AIS $[28,63]$ the cost/effect relation of any therapy, conservative or operative, seems to be a major issue in times of restricted resources in the international health systems [64].

As has been pointed out by Hawes [65], scoliosis sometimes may have desastrous effects on the individual's health, however this is not necessarily the case for most scoliosis cases [28,63].

\section{Methodology of rehabilitation in patients with spinal deformities}

Physical therapy and the application of spinal orthoses are the methods of choice as used in the context of rehabilitation in patients with spinal deformities. Additionally, psychologic support seems necessary by the specialist physician or is offered by psychologists.

\section{Role of exercise in rehabilitation of spinal deformities}

Exercise based therapies (Figure 1, 2 and 3), alone or in combination with orthopaedic approaches, are a logical approach to improve and maintain flexibility and function in patients at risk for pain, pulmonary dysfunction, and progression. Published data reveal improved

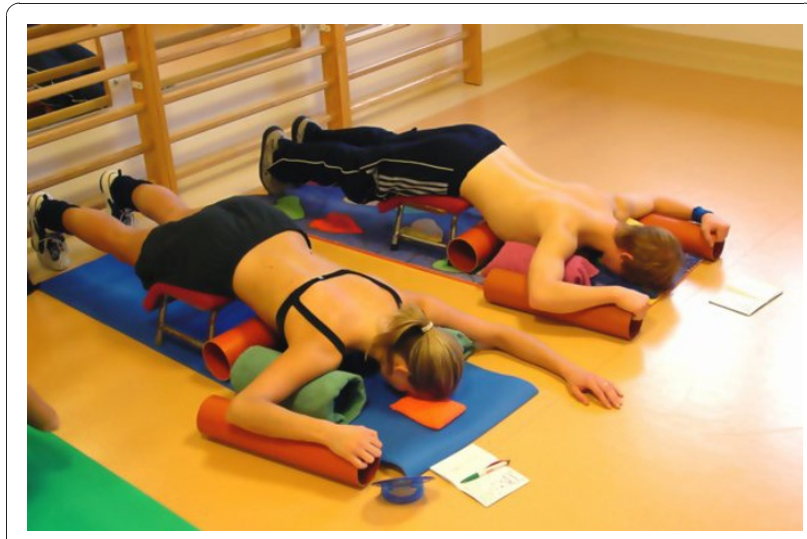

Figure 1 Exercises as performed during inpatient rehabilitation. Many items are needed in order to allow a pattern specific 3 D correction in lying position. Pads, stools, rolls and other items used in lying position are not needed in the new 'Power Schroth' approach used within the 'Best Practice' programme.

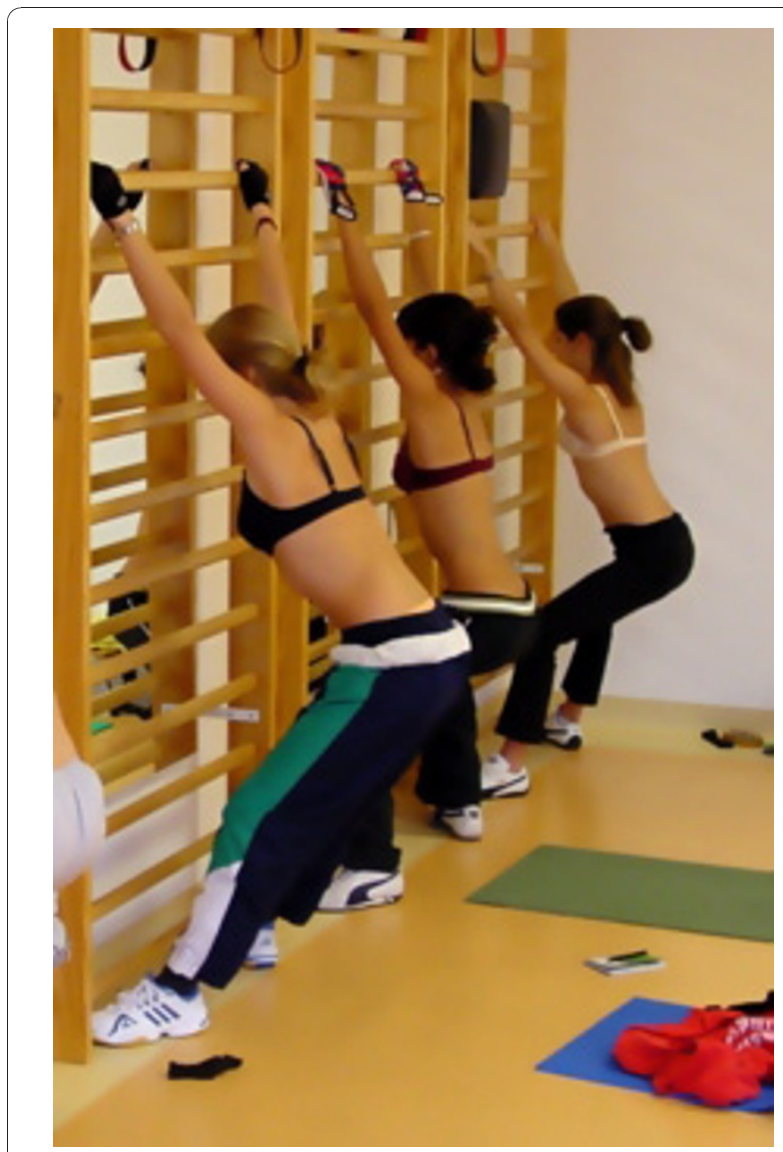

Figure 2 Scoliosis is a 'flatback disorder' and therefore thoracic kyphosis has to be restored. As shown in this example, many of the 'old' Schroth exercises increase the flatback. These exercises are still in use today, although this is not beneficial to AIS (Adolescent Idiopathic Scoliosis) patients with thoracic curvatures.

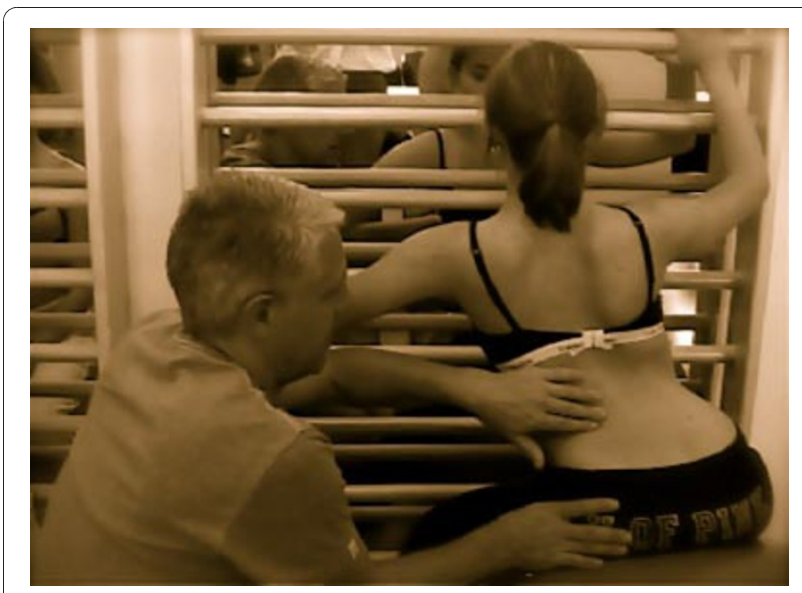

Figure 3 New Power Schroth' exercise using postural synergy effects. Outer rotation of the arm of the thoracic convex side improves derotation and redression of the rib-hump on the same side. Inner rotation of the arm of the thoracic concave side improves kyphosation on the thoracic concave side, which is the 'flatback side' of the curve. 
pulmonary function $[54,66]$ and reduced pain $[67,68]$ in response to scoliosis rehabilitation. Among the small number of studies which have examined this formally [69-76], progression was less in patient populations who were treated with exercise [reviewed in [77]]. When exercise was prescribed but not carried out by the patient, progression was similar to that of untreated populations [73].

The role of exercise based therapies as discussed in the spine literature has been controversial, however, with often repeated claims that research has shown that such approaches are ineffective in treating scoliosis [e.g. [78-90]]. An early systematic review of articles published in English throughout history produced no data in support of such claims [91]. As pointed out by Focarile et al., [92] in 1991, 'Experimental controlled studies of different therapies seem to be justified on both ethical and scientific grounds.'

It was in 1941, when a committee of the American Orthopaedic Association undertook a study of methods and results of treatment of idiopathic scoliosis, by interviewing clinicians at sixteen clinics in the United States [93]. Case histories of 425 patients, followed for $>1$ year after treatment, were evaluated. The goal of the study was to 'establish the present status of this condition, and to clarify, as far as possible, what can be expected from the present methods of treatment.' Short term results obtained with surgery and with exercise were similar, with little or no improvement obtained for most patients.

In the ensuing decades since this study was published, the routine use of exercise for patients in the United States was largely eliminated. Meanwhile, an ongoing global effort to develop effective surgical methods is reflected in $>10,000$ peer reviewed articles published, in English, since 1950 and listed in Medline and other searches for scholarly articles. Unfortunately, the lack of success with exercise reported in 1941, unlike the failure of surgery, has not led to a corresponding effort to define improved methods for using physical therapy to treat patients with scoliosis: A parallel search of Medline revealed that fewer than 150 articles exploring the use of exercise-based approaches in the treatment of scoliosis in patients, of any age, have been published [11].

The routine use of exercise has remained central to therapeutic approaches in many countries [11]. To date, however, the body of literature available to patients and clinicians still seems of limited use $[11,94]$. The relatively limited literature in part reflects clinical traditions, which have not placed a high priority on publication. Perhaps more important, a diversity of approaches, standards, and languages limits how accessible and interpretable the available information is to colleagues with common interests [11]: Among several hundred reports of clinical outcome published in recent decades $(>600)$, no fewer than ten different languages were used. The establishment of a scientific society dedicated to research into scoliosis rehabilitation (SOSORT), and a venue for rigorous peer review of results from specialists, are critical first steps in defining the role of physical therapy in the treatment of scoliosis.

Nevertheless, in the latest updated reviews the use of exercises (Figure 3.) seems to have gained more evidence. When looking at scoliosis treatment including physical therapy, bracing and spinal fusion surgery, there is evidence on level II for conservative treatment and level III evidence, only for spinal fusion surgery [95-97].

In another systematic review Negrini and co-workers have found a randomized controlled trial for physical therapy in scoliosis management in Chinese literature. The authors claim from their findings, that physical therapy should be regarded as being of level I evidence [98].

The role of exercises in the treatment of kyphosis has never been investigated systematically, however, unlike exercises for the treatment of scoliosis, physical treatment of kyphosis patients seems to be accepted widely [99].

\section{The role of spinal orthoses in the rehabilitation of patients with spinal deformities}

The use of spinal orthoses in the rehabilitation of patients with spinal deformities has been discussed controversially [94]. The evidence currently existent has been discussed in a comment [100] to the Cochrane review by Negrini and co-workers [101] as follows:

"Scoliosis is regarded as being a relatively rare condition and when using conservative measures, it cannot always be treated successfully. It would therefore seem likely that professionals accept such failures rather than search for reasons for this in conservative management. For example, Castro [102] claimed that it is necessary to achieve at least a $20 \%$ in-brace correction to stop curvature progression. In lieu of opening a discussion upon how to improve in-brace correction, the author accepted the failure and stated that, when a $20 \%$ correction cannot be achieved, brace treatment should be abandoned in favour of operative treatment.

Whilst there is a wide range of braces available worldwide with many different approaches and theories proposed for each brace design, many of these braces lack evidence to support their use (Figure 4).

What we do know is: the outcome of brace treatment is determined by (1) in-brace correction effects and by (2) compliance of the patient treated [103]. We also know that risk for progression is highest during the pubertal growth spurt [104] and this knowledge has 


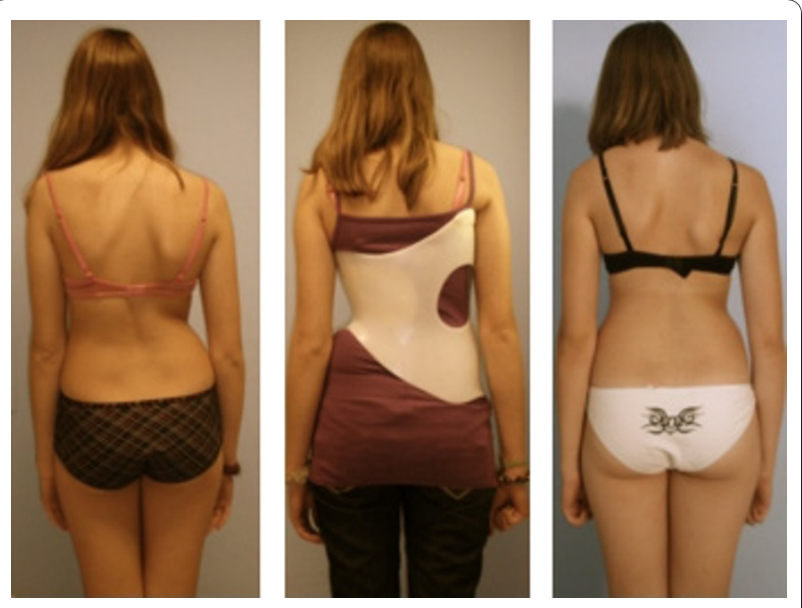

Figure 4 Standard of today's high correction braces. As can be seen on this figure, the deformity of the trunk is mirrored in the Gensingen brace ${ }^{\mathrm{TM}}$, one of the braces enabling correction of the spine and the clinical deviation of the trunk. After six weeks of bracing the deformity is largely reduced (right picture compared to left).

enabled the establishment of evidence-based guidelines for the treatment of scoliosis during growth [104,105]. Finally, we have to accept that while Randomized Controlled Trials (RCTs) have the highest evidence accepted [106], this study design is not appropriate to enable answers for all subsequent questions as has been discussed previously [106]. Neither patient characteristics, nor the very different braces in use today can be standardized enough to allow the application of a RCT.

Failures of $>40 \%$ have been reported in prospective studies $[107,108]$, while in retrospective reports the failure rate has been < 10\% [109-112]. Study designs included patients who, according to the SOSORT guidelines, did not necessarily need any treatment at all and whose authors claimed to have the smallest amount of patients requiring surgery [113]. Studies included patients from 4 to 14 years of age, with very few patients being at actual risk for progression [114]. The most progressive age range in girls with scoliosis is between 11 and 13 years, sometimes earlier. Therefore - also according to the SRS inclusion criteria - most of the population from the study cited would not have needed brace treatment at all. Nevertheless, the authors concluded that the intervention as described was beneficial $[108,115]$, while other prospective controlled studies have included only patients at risk of progression leading to the conclusion that soft braces, presented in these studies [108,115], do not work at all $[116,117]$. Based on these study limitations, it is clear that more homogeneity within the outcome studies is needed to draw evidence-based conclusions.

An unbiased view on scoliosis treatment, not only rests in the study design, but also needs to include the consideration of many factors, determined by the patient samples and the different interventions used. Other factors include; age; gender; maturity; Cobb angle; rotation of the apical vertebra; curve patterns; curve stiffness; and compliance with treatment. The approaches to treatment are another important factor; brace type, specifics, and quality; in-brace correction; and also the appropriate approach to the patient to stimulate and maintain compliance with treatment.

The rarity of the condition, the many factors influencing the outcome of the intervention and the subjective and partly biased view of professionals, make it difficult to gain evidence for or against conservative or surgical treatment [97,118-121]."

For example, the Cochrane review on braces has been flawed for being incomplete. The authors did not include a prospective controlled trial with patient samples at actual risk for being progressive [100]. This study contains two homogenous groups of patients (girls, first signs of maturity), all premenarchial and fulfilling the SRS inclusion criteria for studies on bracing at least for the group of patients wearing the hard braces.

Interestingly, bracing in kyphosis patients has not been questioned to that extent [99], although there is much less evidence in international literature for kyphosis braces than for scoliosis braces [101].

Braces today are becoming more and more comfortable [122] and reliable with respect to in-brace correction effects [123-126] and seem to be able to also improve cosmesis (Figure 5)

\section{History of the rehabilitation of spinal deformities}

Mechanical approaches have been used in ancient times. The table of Hippocrate (http://www.scoliosisjournal. com/content/4/1/6/figure/F18) and the suspension of scoliosis patients http://www.scoliosisjournal.com/content/4/1/6/figure/F14 have been used for many decades [127].

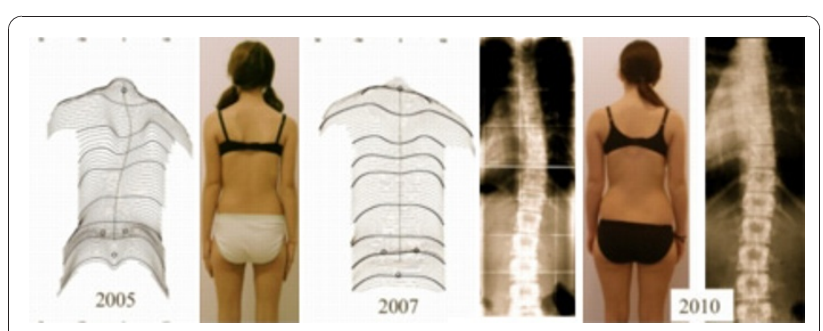

Figure 5 Example of a patient with an initial overcorrection in a Chêneau light brace. Left (2005) at begin with $38^{\circ}$, middle (2007) compensated appearance with $18^{\circ}$ and finally right (2010) after weaning off (at 16 years of age) with a balanced clinical appearance the curve was $12^{\circ}$ (right). Weiss and Werkmann Scoliosis 2010 5:19 doi: 10.1186/1748-7161-5-1 
At the beginning of the $20^{\text {th }}$ century, different approaches of physiotherapy were used in the treatment of single patients (Figure 6), whilst since 1921, 3 to 6 months of rehabilitation in a group setting has been implemented by Katharina Schroth in Meißen, Germany $[128,129]$. There are case reports showing that with the Schroth approach, performed for some months, encouraging results have been achieved even in curvatures exceeding $100^{\circ}$ Cobb (Figure 7 ).

In the 60's, 70's and 80's reasonable results were achieved and documented, even without the application of - at that time - braces of questionable quality. Case reports have been published in the book by LehnertSchroth, mother of the author and daughter of Katharina Schroth [129].

The rehabilitation of scoliosis patients has been subject of several investigations [66-68,70-72,75] and finally, it was possible to compare the results of a cohort treated between 1989 and 1991 followed up prospectively, to an untreated control group followed up prospectively from the same country [76]. The rate of progression has been reduced significantly in the group undergoing inpatient rehabilitation; however there still was a high proportion of patients with progression after in-patient rehabilitation.

While rehabilitation times have been reduced up to the end of the 90's [130], at the same time, the standard of bracing improved drastically in Germany. The development started in 1995 with new brace designs as implemented by Dr. Chêneau, who presented these at regular courses [126].

While the latest standards of specific braces show encouraging in-brace correction [123-126] and end results [123], in-patient rehabilitation with treatment times of 4 weeks or less and with programmes that have

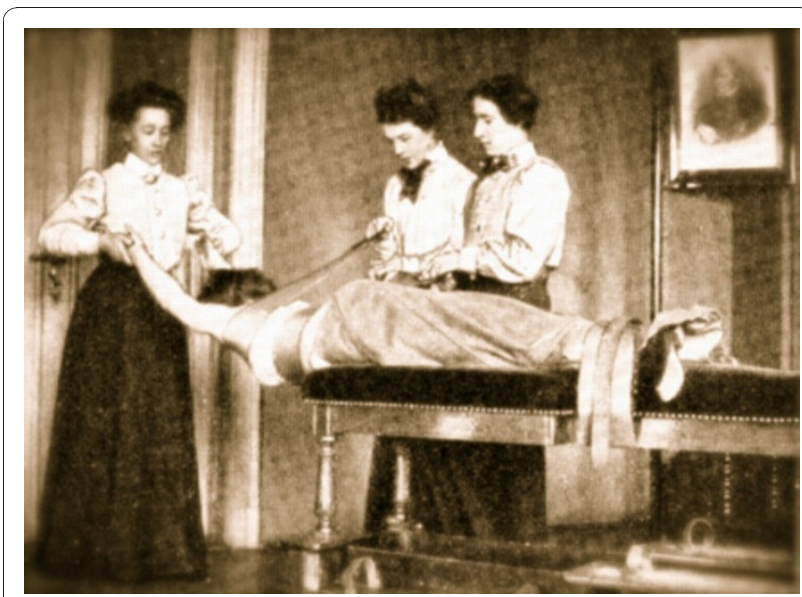

Figure 6 Three therapists treat one patient in the setting proposed by Oldevig at the beginning of the 20th century.

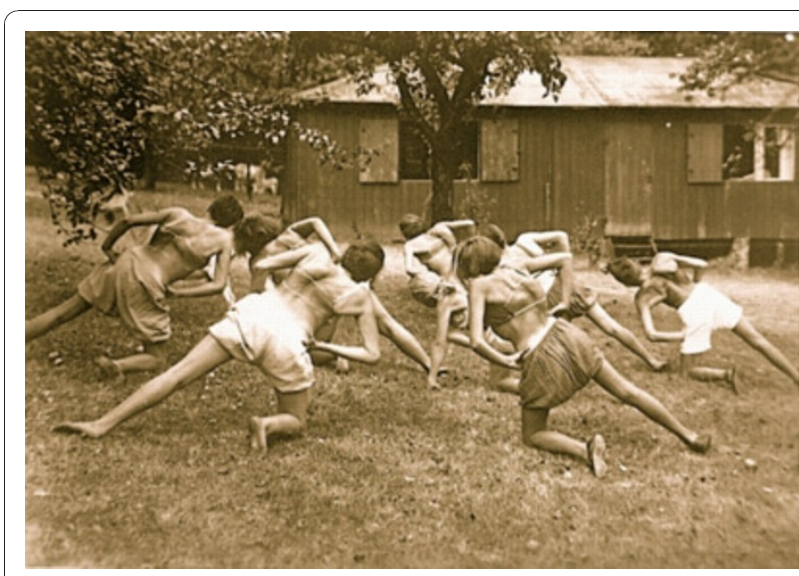

Figure 7 Group rehabilitation therapy as proposed by Katharina Schroth. The pattern specific programme has been taught to the patients so as to enable them to follow the instructions of the therapist during the group setting.

been widely changed presently seem to lack evidence [130].

As early as in 2006 it has been shown that rehabilitation time can be reduced significantly without further loss of outcome [131] and that the original programme can be easily improved by applying a new method to address the sagittal profile as an add-on [132].

Today, for both children and adolescents, we are able to offer intensive rehabilitation programmes lasting three to five days, which enable the patients to acquire the skills necessary to prevent postures fostering scoliosis in everyday life [133].

Nevertheless, in view of the fact that there are adolescent patients complying with bracing, who will have a beneficial outcome of treatment even without physiotherapy or in-patient rehabilitation, the issue of scoliosis rehabilitation will have to be analysed in more detail.

In times of reduced resources, the cheapest procedure of rehabilitation would be an appropriate brace worn according to the suggestions made in the SOSORT guidelines.

However, as long-term brace compliance is not easy to achieve, the supportive effect of group rehabilitation cannot be neglected [133].

Adults with scoliosis have been undergoing in-patient rehabilitation from the very start of such programmes $[128,129]$. There are in fact, many positive case reports showing successful outcomes after three months of rehabilitation in the little centre of Katharina Schroth in Meißen before World War II [129].

Contrary to adolescents or children with scoliosis, who have been shown to have beneficial outcomes after Scoliosis Short-term Rehabilitation (SSTR) [133], the secondary functional impairments adult scoliosis 
patients might have, in the author's opinion, even today need the time of 3-4 weeks in the clinical in-patient setting. Time to address psychosocial as well as somatic limitations, like chronic pain and cardiorespiratory malfunction is needed to keep the patients working, although final evidence for this is also lacking [130].

Nevertheless, the author has seen thousands of adult patients kept in work because of the positive impact of regular four-week rehabilitations with an intensive programme [134].

\section{Outcomes of spinal deformities rehabilitation}

Today, there is no evidence that in-patient rehabilitation of patients with spinal deformities is superior to outpatient conservative management [130]. Although in the setting of in-patient rehabilitation it seems easier to reach the goals set with the help of multimodal approaches including psychological interventions, the outcome of today's in-patient rehabilitation does not seem superior to out-patient conservative management.

Retrospective studies show no difference between inand out-patient management with respect to the surgical rate in children and adolescents with scoliosis. Surgical rates were roughly the same in a sample of patients treated as in-patients [111] as in three samples of patients treated in the out-patient mode [109,110,112].

A prospective study with a sample of patients undergoing in-patient rehabilitation of 6 weeks between 1989 and 1991, and a control group of patients not undergoing any treatment, reveals significant differences with respect to the progression rate [76], however neither length, nor intensity of the in-patient treatment is comparable to what is applied today [130].

A randomized controlled study as reported by Negrini and coworkers shows that out-patient physiotherapy in fact has a beneficial impact on patients with scoliosis in the mid-term [98], therefore the highest level of evidenced has been found for out-patient rehabilitation/ physiotherapy.

Although the sample of patients in the study by Otman et al. [135] does not seem to be immature enough to draw final conclusions, the authors report improvements not only with respect to curvature, but also with respect to vital capacity, as has been shown in another study on in-patient rehabilitation [66].

Prospective controlled studies in a pre-/post design show, that scoliosis in-patient rehabilitation can be improved with specific add-ons and rehabilitation times can be reduced significantly without any loss of effectiveness [131,132].

Nevertheless, psychosocial issues may be better addressed in patients undergoing in-patient rehabilitation. However, evidence for this is weak $[136,137]$.
There are studies demonstrating beneficial effects of in-patient rehabilitation in patient samples from the late 80 's to the early 90's in patient samples undergoing treatment times of 6 weeks. Pain was reduced $[67,68]$ and vital capacity significantly increased [66]. It has also been shown in a cohort study with a pre-/post-design that right cardiac strain was reduced after in-patient rehabilitation of 6 weeks.

Also curvature angles were improved during in-patient rehabilitation [71].

When reviewing literature, no long-term results of inpatient rehabilitation are available [130]. A prospective controlled study with adolescent patient samples from the years 1989 - 1991 has shown a beneficial mid-term effect of in-patient rehabilitation of 6 weeks compared to untreated controls [76].

For rehabilitation procedures applied today with reduced rehabilitation times and modified methodology no studies exist to support these interventions [130] and therefore it seems questionable as to whether the results mainly achieved in the years 1989 and 1991 can be achieved in todays setting of in-patient rehabilitation with reduced rehabilitation times, changed methodology and today's patient samples not being as motivated as in the 80's [76].

\section{Suggestions for a differential indication Children and adolescents with spinal deformities}

Children and adolescents with spinal deformities without further limitations have to be treated according to the indication guidelines [104]. Overtreatment as well as undertreatment can be avoided when these guidelines are respected. In case there is an indication for physiotherapy, outpatient programmes are recommended (1) to avoid brace treatment or, in case of a brace indication (2) to support mobility of the spine as well as the compliance of the patients (Figure 8 and 9). In patients under brace treatment more intensive rehabilitation programmes are recommended [104], however these according to current evidence - do not necessarily need to last a few weeks. Three to five day programmes have been tested successfully [133], but the author has also experienced beneficial outcomes of conservative treatment without any physiotherapy in patients with braces of best possible in-brace corrections. Brace treatment in the population with brace indication is surely the major issue and physiotherapy is secondary. Therefore, we should not overload our patients under brace treatment and with a good compliance with additional measures of questionable benefit. However, when rehabilitation of this special group of patients is indicated, the rehabilitation of daily activities - especially the rehabilitation of walking - is essential, as skills in corrective walking 


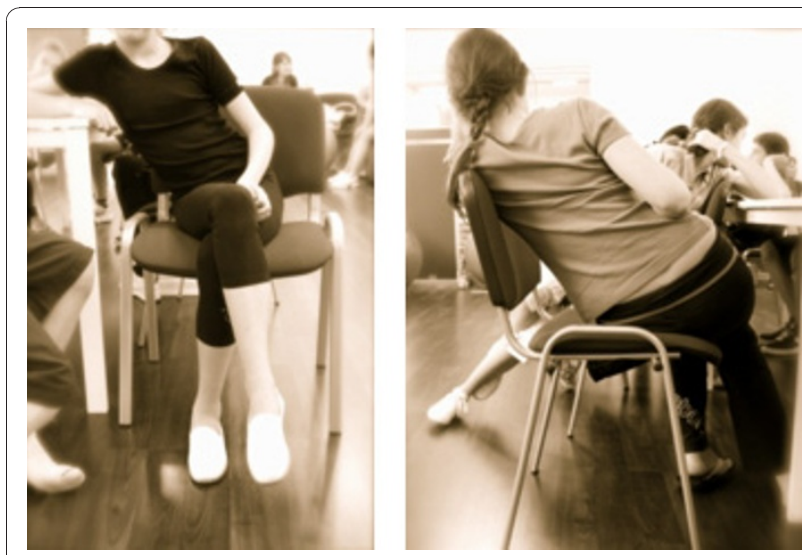

Figure 8 Activities of daily living (ADL) as trained within modern Scoliosis Short-term Rehabilitation (SSTR). Corrected posture in standing, sitting and walking are essential to enable the patients to avoid postures in daily activities fostering curve progression. The SSTR is also taught to professionals regularily. Short impressions of the Scoliosis Short-Term Rehabilitation (SSTR) as described [133] can be found at: [144-146]. Impression of the courses given for professionals can be found here: $[147,148]$.

helps to gain the appropriate feeling for corrected posture in ADL (Figure 10).

The specialist guiding the patient has to have superior psychological skills, because a failure of brace treatment is not necessarily a brace failure, but in most cases fault of the physician [137].

\section{Adolescents and adults with chronic back pains}

Adolescents and adults with chronic back pains, require as well as physical treatment, psychological support $[67,68,136,138]$. Sometimes, the application of specific braces is also necessary $[139,140]$. Although there is no evidence that chronic pains can be treated more

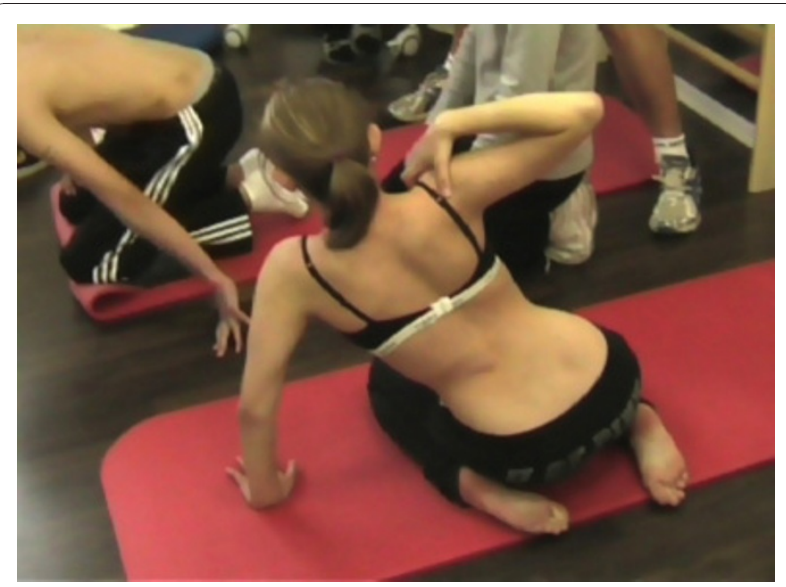

Figure 9 A 'New Power Schroth' exercise to improve postural control of the patient treated. This exercise, called ' Frog at the pond' enables the patient to achieve the skills necessary to improve postural control during ADL [146]

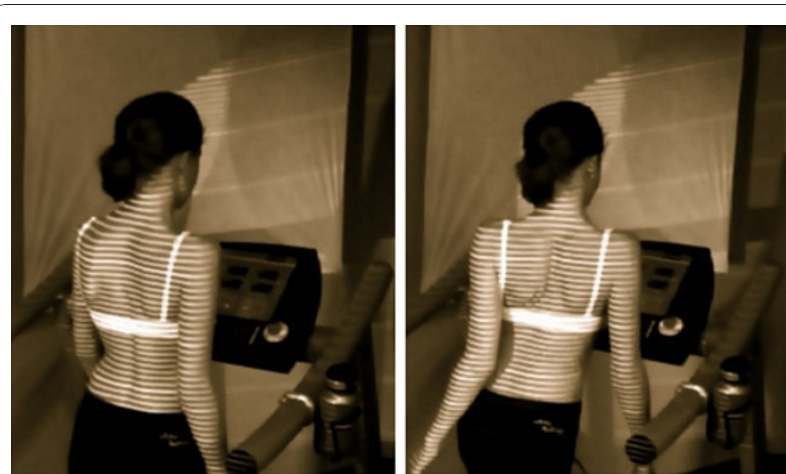

Figure 10 Corrective movements trained during walking. Scoliosis 3 D correction can be performed in sitting and also standing position, however the highest skill is correcting the deformity of the spine and trunk whilst walking. This can be performed using a treadmill, but also by walking plainly on the ground. This is also shown on a video [144].

efficiently in the inpatient setting for patients with scoliosis and pain as to the authors opinion the safe environment of an inpatient centre should be chosen, because these patients have to cope with two different issues at the same time, deformity and pain, which require more complex approaches than for the rehabilitation of pain alone. The major aim of in-patient rehabilitation of adult patients with deformity pain is to preserve the patients working capability in the longterm.

Every inpatient centre specializing in pain management and with experience in scoliosis treatment will be able to address the problems and limitations of this specific group of patients accordingly [141].

Adolescents and adults with restrictive ventilation disorders Adolescents and adults with restrictive ventilation disorders usually have severe thoracic deformities and lack rib mobility and vital capacity [11]. Both of these problems can only be addressed in specialized centres with superior knowledge in the field of rehabilitation of breathing. It has been demonstrated that vital capacity, rib mobility [66] and cardiopulmonary function [54] can be improved by undergoing an intensive inpatient rehabilitation programme lasting 6 weeks. While it is not clear as to whether 3 to 4 week programmes may have the same effect as the 6 week programme investigated in the 80's and 90's of the last century, inpatient rehabilitation should be performed in this group of patients as these patients have to cope with two different issues at the same time, deformity and restrictive ventilation disorder, which may require more complex approaches than for the rehabilitation of deformity alone.

\section{Postoperative rehabilitation}

Postoperative rehabilitation is rarely necessary. On the one hand direct postoperative mobility and activities of 
the patients' should be limited for a year in order to ensure a safe healing and stabilization of the bone structure. On the other hand, mobility of the spine as a whole and on the segmental level as well is largely reduced after operation. Problems within the fusion area cannot be addressed by physical means, manipulation of fused segments is obsolete and pain related to costotranversal joint problems can hardly be mobilized without stress to the fusion area.

Nevertheless, there is little evidence that operated patients with chronic back pain can benefit from inpatient rehabilitation [138]. The junctional zones (fused area/unfused area) of the spine can be stabilized and obviously pain can be reduced [138]. For the rehabilitation of operated patients with spinal deformities only specialized centres are recommended to assure maximum patient safety.

High quality rehabilitation with the help of exercises, re-education and high quality bracing may reduce the costs the community has to bear when surgical intervention can be avoided [142]. Finally it's the surgical intervention causing the highest costs after low quality conservative management has failed [142,143].

\section{Conclusions}

There is little evidence that physiotherapy is beneficial in the treatment of patients with scoliosis.

There is some evidence that braces can stop curvature progression.

There is no evidence that in-patient rehabilitation today is superior to out patient conservative therapy.

Outpatient treatment/rehabilitation is sufficient for adolescents with spinal deformities without further limitations.

Inpatient rehabilitation is recommended for patients with spinal deformities and pain or severe restrictive ventilation disorder.

\section{Consent}

Written informed consent was obtained from the patients and their next of kin for publication of of their data within this review and accompanying images. A copy of the written consent is available for review by the Editor-in-Chief of this journal.

\section{Acknowledgements \\ The author wishes to thank Lesley Schneider for copyediting this paper.}

\section{Competing interests}

The author is applying for some patents relating to the content of this paper and is advisor of Koob-Scolitech, Abtweiler, Germany.

Received: 5 November 2010 Accepted: 24 December 2010 Published: 24 December 2010

\section{References}

1. Baron S, Linden M: Analyzing the Effectiveness of Inpatient Psychosomatic Rehabilitation Using the Mini-ICF-APP. Rehabilitation 2009, 48:145-153.

2. Hüppe A, Raspe H: Die Wirksamkeit stationärer medizinischer Rehabilitation in Deutschland bei chronischen Rückenschmerzen: eine systematische Literaturübersicht 1980 - 2001. Rehabilitation 2003, 42:143-154.

3. Lehmann C, Bergelt C, Welk H, Hagen-Aukamp C, Berger D, Koch U: Unterscheiden sich ambulante und stationäre onkologische Rehabilitationsmaßnahmen im Hinblick auf Leistungserbringung und Erfolg? Eine Analyse der medizinischen Entlassungsberichte. Phys Rehab Kur Med 2008, 18:59-68.

4. Schönle PW: Ambulante und stationäre neurologische Rehabilitation ein katamnestischer Vergleich. Rehabilitation 2002, 41:183-188.

5. Bürger W, Dietsche S, Morfeld M, Koch U: Ambulante und stationäre orthopädische Rehabilitation - Ergebnisse einer Studie zum Vergleich der Behandlungsergebnisse und Kosten. Rehabilitation 2002, 41:92-102.

6. vom Orde A, Schott T, Iseringhausen O: Behandlungsergebnisse der kardiologischen Rehabilitation und Kosten-Wirksamkeits-Relationen - Ein Vergleich stationärer und ambulanter Versorgungsformen. Rehabilitation 2002, 41:119-129.

7. Bölsche F, Hasenbein U, Reißberg H, Schlote A, Wallesch CW: Ergebnisse der ambulanten und stationären Rehabilitation in den ersten sechs Monaten nach Schlaganfall. Fortschr Neurol Psychiatr 2003, 71:458-468.

8. Klingelhöfer HE, Lätzsch A: Wirtschaftlichkeitsvergleich ambulante versus stationäre Rehabilitation. Gesundheitswesen 2003, 65:163-166.

9. Maier-Riehle B, Schliehe F: Der Ausbau der ambulanten Rehabilitation. Rehabilitation 2002, 41:76-80.

10. Nordström DC, Konttinen YT, Solovieva S, Friman C, Santavirta S: In- and out-patient rehabilitation in rheumatoid arthritis. A controlled, open, longitudinal, cost-effectiveness study. Scand J Rheumatol 1996, 25(4):200-6.

11. Weiss HR, Negrini S, Hawes MC, Rigo M, Kotwicki T, Grivas TB, Maruyama T: Physical exercises in the treatment of idiopathic scoliosis at risk of brace treatment - SOSORT consensus paper 2005. Scoliosis 2006, 1:06.

12. Ascani E, Bartolozzi P, Logroscino CA, Marchetti PG, Ponte A, Savini R, Travaglini F, Binazzi R, Di Silvestre M: Natural history of untreated IS after skeletal maturity. Spine 1986, 11:784-789.

13. Collis DK, Ponseti IV: Long-term follow-up of patients with IS scoliosis not treated surgically. J Bone Jt Surg 1969, 51-A:425-445.

14. Fowles JV, Drummond DS, L'Ecuyer S, Roy L, Kassab MT: Untreated scoliosis in the adult. Clinical Orthop Related Res 1978, 134:212-22.

15. Nachemson A: A long term follow-up study of nontreated scoliosis. Acta Orthop Scan 1968, 39:466-476.

16. Balague F, Dutoit $G$, Waldburger M: Low back pain in schoolchildren. An epidemiological study. Scandinavian J Rehab Med 1988, 20:175-179.

17. Edgar MA: Back pain assessment from a long term follow-up of operated and unoperated patients with AIS. Spine 1979, 4:519-521.

18. Fairbank JC, Pynsent PB, Van Poortvliet JA, Phillips H: Influence of anthropometric factors and joint laxity in the incidence of adolescent back pain. Spine 1984, 9:461-464

19. Kostuik JP, Bentivoglio J: The incidence of low back pain in adult scoliosis. Spine 1981, 6:268-273.

20. Jackson RP, Simmons EH, Stripinis D: Incidence and severity of back pain in adult idiopathic scoliosis. Spine 1983, 8:749-756.

21. Mayo NE, Goldberg MS, Poitras B, Scott S, Hanley J: The Ste-Justine AIS cohort study. Part III: Back pain. Spine 1994, 14:1573-1581.

22. Nastasi AJ, Levine DB, Veliskakis KP: Pain patterns in AIS. J Bone Jt Surg 1972, 54-A:1575

23. Nilsonne $U$, Lundgren K: Long term prognosis in IS. Acta orthop Scandinav 1968, 39:456-465.

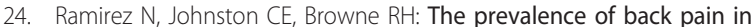
children who have IS. J Bone Jt Surg 1997, 79-A:364-368.

25. Vitale MG, Levy DE, Johnson MG, Gelijns AC, Moskowitz AJ, Roye BP, Verdisco L, Roye DP: Assessment of quality of life in adolescent patients with orthopedic problems: Are adult measures appropriate? J Ped Orthop 2001, 21:622-628.

26. Weinstein SL, Zavala DC, Ponseti IV: Idiopathic scoliosis: long term followup and prognosis in untreated patients. J Bone Jt Surg 1981, 63A:702-712. 
27. Goldberg MS, Mayo NE, Poitras B, Scott S, Hanley J: The Ste-Justine Adolescent Idiopathic Scoliosis Cohort Study. Part II: Perception of health, self and body image, and participation in physical activities. Spine 1994, 14:1562-1572.

28. Weinstein SL, Dolan LA, Spratt KF, Peterson KK, Spoonamore MJ, Ponseti IV: Health and function of patients with untreated IS: a 50-year natural history study. JAMA 2003, 289:559-567.

29. Bishop C: Where are the missing elders? The decline in nursing home use, 1985-1995. Health Affairs 1999, 18:146-155.

30. Weinstein SL: Health and function with untreated scoliosis - reply. JAMA 2003, 289:2644.

31. Deviren V, Berven S, Kleinstueck F, Antinnes J, Smith JA, Hu SS: Predictors of flexibility and pain patterns in thoracolumbar and lumbar IS. Spine 2002, 27:2346-2349.

32. Schwab FJ, Smith VA, Biserni M, Gamez L, Farcy JP, Pagala M: Adult scoliosis:quantitative radiographic and clinical analysis. Spine 2002, 27:387-392.

33. Chong KC, Letts RM, Cumming GR: Influence of spinal curvature on exercise capacity. J Ped Orthop 1981, 1:251-254.

34. DiRocco P, Breed AL, Carlin Jl, Reddan WG: Physical work capacity in adolescents with mild IS. Arch Phys Med Rehab 1983, 64:476-479.

35. DiRocco P, Vaccaro P: Cardiopulmonary functioning in adolescent patients with mild IS. Arch Phys Med Rehab 1988, 69:198-199.

36. Smyth RJ, Chapman KR, Wright TA, Crawford JS, Rebuck AS: Pulmonary function in adolescents with mild IS. Thorax 1984, 39:901-904.

37. Smyth RJ, Chapman KR, Wright TA, Crawford MD, Rebuck AS: Ventilatory patterns during hypoxia, hypercapnia, and exercise in adolescents with mild scoliosis. Pediatrics 1986, 77:692-696.

38. Szeinberg A, Canny GJ, Rashed N, Veneruso G, Levison H: Forced VC and maximal respiratory pressures in patients with mild and moderate scoliosis. Ped Pulmon 1988, 4:8-12.

39. Weber B, Smith JP, Briscoe WA, Friedman SA, King TKC: Pulmonary function in asymptomatic adolescents with IS. Am Rev Resp Dis 1975, 111:389-397.

40. Fraser RS, Muller NL, Colman N, Pare PD: Fraser and Pare's Diagnosis of Diseases of the Chest. Fourth edition. Philadelphia: WB Saunders; 1999.

41. Murray JF, Nadel JA: Textbook of Respiratory Medicine. 3 edition. Philadelphia: WB Saunders; 2000.

42. Branthwaite MA: Cardiorespiratory conequences of unfused IS. Br J Dis Chest 1986, 80:360-369.

43. Davies G, Reid L: Effect of scoliosis on growth of alveoli and pulmonary arteries and on the right ventricle. Archives of Disease in Childhood 1971, 46:623-632.

44. Hitosugi M, Shigeta A, Takatsu A: An autopsy case of sudden death in a patient with IS. Medicine Science and the Law 2000, 40:175-178.

45. Pehrsson K, Larsson S, Oden A, Nachemson A: Long term follow-up of patients with untreated scoliosis. A study of mortality, causes of death and symptoms. Spine 1992, 17:1091-1096.

46. Schneerson JM, Sutton GC, Zorab PA: Causes of death, right ventricular hypertrophy, and congenital heart disease in scoliosis. Clin Orth Rel Research 1978, 135:52-57.

47. Dickson RA: Spinal deformity - AIS. Nonoperative treatment. Spine 1999, 24:2601-2606.

48. Dickson RA, Weinstein SL: Bracing (and screening) - yes or no? J Bone Jt Surg 1999, 81-B:193-198.

49. Mannino DM, Buist AS, Petty TL, Enright PL, Redd SC: Lung function and mortality in the U.S.: data from the First National Health and Nutrition Examination Survey followup study. Thorax 2003, 58:388-393.

50. Karlson BW, Sjolin M, Lindqvist J, Caidahl K, Herlitz J: Ten-year mortality rate in relation to observations of a bicycle exercise test in patients with a suspected or confirmed ischemic event but no or only minor myocardial damage. American Heart Journal 2001, 141:977-984

51. Myers J, Prakash M, Froelicher V, Do D, Partington S, Atwood JE: Exercise capacity and mortality among men referred for exercise testing. New England Journal of Medicine 2002, 346:793-801.

52. Collis DK, Ponseti IV: Long-term follow-up of patients with IS scoliosis not treated surgically. J Bone Jt Surg 1969, 51-A:425-445.

53. Drummond DS, Rogala E, Gurr J: Spinal deformity: Natural history and the role of screening. Orthop Clinics of NA 1979, 10:751-759.

54. Weiss HR, Bickert W: Improvement of the parameters of right-heart stress evidenced by electrocardiographic examinations by the in-patient rehabilitation program according to Schroth in adult patients with scoliosis. Orthop Prax 1996, 32:450-453.

55. Roaf R: Scoliosis Baltimore: Williams and Wilkins; 1966

56. Stokes IAF: Hueter-Volkmann Effect. State of the Art Reviews. Spine 2000, 14:349-357.

57. Stokes IAF, Gardner-Morse M: The role of muscles and effects of load on growth. Research into Spinal Deformity 2002, 4:314-317.

58. Lonstein JE, Carlson JM: The prediction of curve progression in untreated idiopathic scoliosis during growth. J Bone Jt Surg [Am] 1994, 66:1061.

59. Weinstein SL: Natural history. Spine 1999, 24:2592-2600.

60. Bjerkreim R, Hassan I: Progression in untreated IS after the end of growth. Acta Orthop Scand 1982, 53:897-900.

61. Weinstein SL, Ponseti IV: Curve progression in IS. Bone Jt Surg 1983, 65A:447-455

62. Lonstein JE, Winter RB: AIS: Nonoperative treatment. Orth Clinics NA 1988, 19:239-245.

63. Asher MA, Burton DC: Adolescent idiopathic scoliosis: natural history and long term treatment effects. Scoliosis 2006, 1(1):2

64. Weiss HR, Goodall D: Total case management - the key to really etimate cost effectiveness in certain orthopedic conditions in Germanys health system. The Internet Journal of Healthcare Administration 2010, 7:1.

65. Hawes MC: The use of exercises in the treatment of scoliosis: an evidence-based critical review of the literature. Pediatric Rehabilitation 2003, 6(3-4):171-82.

66. Weiss HR: The effect of an exercise programme on VC and rib mobility in patients with IS. Spine 1991, 16:88-93.

67. Weiss HR: Scoliosis related pain in adults - treatment influences. Eur Phys Med and Rehab 1993, 3:91-94.

68. Weiss HR, Verres C, Lohschmidt K, El Obeidi N: Pain and scoliosis - is there any relationship? Orthop Prax 1998, 34:602-606.

69. Ferraro C, Masiero S, Venturin A: Effect of exercise therapy on mild idiopathic scoliosis. Preliminary result. Europa Medico Physica 1998, 34:25-31.

70. Rigo M, Quera-Salva G, Puigdevall N: Effect of the exclusive employment of physiotherapy in patients with idiopathic scoliosis. Proceedings Book III of the 11th International Congress ofthe World Confederation for Physical Therapy:July28th - August 2nd. 1991 London, Chartered Society of Physiotherapists; 1991, 1319-1321.

71. Weiss HR: Influence of an in-patient exercise program on scoliotic curve. Italian Journal of Orthopedics and Traumatology 1992, 18:395-406.

72. Weiss HR: The Progression of Idiopathic Scoliosis unter the influence of a Physiotherapy Rehabilitation Program. Physiotherapy 1992, 78:815-821.

73. Stone B, Beekman C, Hall V, Guess V, Brooks HL: The effect of an exercise program on change in curve in adolescents with minimal idiopathic scoliosis. A preliminary study. Physical Therapy 1979, 59:759-763.

74. Den Boer WA, Anderson PG, Limbeek : Treatment of idiopathic scoliosis with side-sthift therapy: an initial comparison with a brace treatment historical cohort. Eur Spine J 1999, 8:406-410.

75. Weiss HR, Lohschmidt K, El Obeidi N, Verres C: Preliminary results and worst-case analysis of inpatient scoliosis rehabilitation. Pediatr Rehabil 1997, 1(1):35-40.

76. Weiss HR, Weiss G, Petermann F: Incidence of curvature progression in idiopathic scoliosis patients treated with scoliosis in-patient rehabilitation (SIR): an age- and sex-matched controlled study. Pediat Rehabil 2003, 1(6):23-30.

77. Negrini S, Antonini G, Carabalona R, Minozzi S: Physical exercises as a treatment for adolescent idiopathic scoliosis. A systematic review. Pediatr Rehabil 2003, 6:227-235.

78. Bleck E: AIS. Developmental Med Child Neurol 1991, 33:167-176.

79. Boachie-Adjei O, Onner B: Spinal Deformity (Common Orthopedic Problems I). Ped Clinics NA 1996, 43:883-897.

80. Bunnell WP: Nonoperative treatment of spinal Deformity ofspinal Deformity: the case for observation. Instructional Course Lectures 1985, 34:106-109.

81. Farady JA: Current principles in the nonoperative management of structural AIS. Physical Therapy 1983, 63:512-523.

82. Haasbeek JF: AIS; recognizing patients who need treatment. Postgraduate Medicine 1997, 101:207-216.

83. Kaelin DL, Oh TH, Lim PAC: Rehabilitation of orthopedic and rheumatologic disorders. 4. Musculoskeletal disorders. Arch Phys Med Rehab 2000, 81:73-77. 
84. Killian JT, Mayberry S, Wilkinson L: Current concepts in AIS. Pediatric Annals 1999, 28:755-761.

85. Leatherman K, Dickson R: The Management of Spinal Deformities London, Boston, Singapore, Sydney, Toronto, Wellington: Wright Press; 1988.

86. Lonstein JE: AIS. Lancet 1994, 344:1407-1412

87. Lonstein JE: Patient Evaluation. In Moe's Textbook of Scoliosis and Other Spinal Deformities.. 3 edition. Edited by: Lonstein JE, Bradford D, Winter R, Oglivie J. Philadelphia: WB Saunders; 1995:45-86.

88. Reamy BV, Slakey JB: AIS: review and current concepts. American Family Physician 2001, 64:111-116.

89. Rinsky LA: Advances in management of IS. Hospital Practice 1992, 49-55.

90. Rinsky LA, Gamble JG: AIS. Western J Med 1988, 148:182-191.

91. Roach JW: Disorders of the pediatric and adolescent spine. Orthop Clinics NA 1999, 30:353-65.

92. Focarile FA, Bonaldi A, Giarolo MA, Ferrari U, Zilioli E, Ottaviani C: Effectiveness of nonsurgical treatment for IS; overview of available evidence. Spine 1991, 16:395-401.

93. Shands AR, Barr JS, Colonna PC, Noall L: End-result study of the treatment of idiopathic scoliosis. Report of the Research Committee of the American Orthopedic Association. J Bone Jt Surg 1941, 23-A:963-977.

94. Moen KY, Nachemson AL: Treatment of scoliosis: an historical perspective. Spine 1999, 24:2570-2575.

95. Weiss HR: Is there a body of evidence for the treatment of patients with Adolescent Idiopathic Scoliosis (AIS)? Scoliosis 2007, 2:19.

96. Weiss HR: Adolescent idiopathic scoliosis (AIS) - an indication for surgery? A systematic review of the literature. Disabil Rehabil 2008, 30:799-807.

97. Weiss HR, Goodall D: The treatment of adolescent idiopathic scoliosis (AIS) according to present evidence. A systematic review. Eur J Phys Rehabil Med 2008, 44(2):177-193.

98. Negrini S, Fusco C, Minozzi S, Atanasio S, Zaina F, Romano M: Exercises reduce the progression rate of adolescent idiopathic scoliosis: Results of a comprehensive systematic review of the literature. Disabil Rehabil 2008, 30:772-785.

99. Bradford DS, Moe JH, Montalvo FJ, Winter RB: Scheuermann's kyphosis and roundback deformity: Results of Milwaukee brace treatment. J Bone Joint Surg [Am] 1974, 56:740-58

100. Weiss HR, Turnbull D: Commentary on the paper entitled; "Braces for idiopathic scoliosis in adolescents," by Stefano Negrini, Silvia Minozzi, Josette Bettany-Saltikov, Fabio Zaina, Nachiappan Chockalingam, Theodoros B. Grivas, Tomasz Kotwicki, Toru Maruyama, Michele Romano, Elias S. Vasiliadis. Evid.-Based Child Health 2010, 5:1723-1725.

101. Negrini S, Minozzi S, Bettany-Saltikov J, Zaina F, Chockalingam N, Grivas TB, Kotwicki T, Maruyama T, Romano M, Vasiliadis ES: Braces for idiopathic scoliosis in adolescents. Cochrane Database Syst Rev 2010, 1: CD006850

102. Castro FP Jr: Adolescent idiopathic scoliosis, bracing, and the HueterVolkmann principle. Spine J 2003, 3:180-5.

103. Landauer F, Wimmer C, Behensky H: Estimating the final outcome of brace treatment for idiopathic thoracic scoliosis at 6-month follow-up. Pediatric Rehabilitation 2003, 6(3-4):201-7.

104. Weiss HR, Negrini S, Rigo M, Kotwicki T, Hawes MC, Grivas TB, Maruyama T, Landauer F: Indications for conservative management of scoliosis (guidelines). Scoliosis 2006, 1:05.

105. Oxford Centre for Evidence-based Medicine, Levels of Evidence (May 2001). [http://www.cebm.net/?o=1011].

106. Weiss HR: Debate on: Bracing in Adolescent Scoliosis Trial (BrAIST) - will the expenditure pay? 6th International Conference on Conservative Management of Spinal Deformites, May 21-23, 2009 - Lyon, France [http:// www.sosort-lyon.net/pdf/saa70.pdf].

107. Bullmann V, Halm HF, Lerner T, Lepsien U, Hackenberg L, Liljenqvist U: Prospective evaluation of braces as treatment in idiopathic scoliosis. $Z$ Orthop Ihre Grenzgeb 2004, 142(4):403-9.

108. Coillard C, Vachon V, Circo AB, Beauséjour M, Rivard CH: Effectiveness of the SpineCor brace based on the new standardized criteria proposed by the scoliosis research society for adolescent idiopathic scoliosis. J Pediatr Orthop 2007, 27(4):375-9.

109. Rigo M, Reiter C, Weiss HR: Effect of conservative management on the prevalence of surgery in patients with adolescent idiopathic scoliosis. Pediatric Rehabilitation 2003, 6:209-214.

110. Maruyama T, Kitagawa T, Takeshita K, Mochizuki K, Nakamura K: Conservative treatment for adolescent idiopathic scoliosis: can it reduce the incidence of surgical treatment? Pediatric Rehabilitation 2003, 6(34):215-9.

111. Weiss HR, Weiss G, Schaar HJ: Incidence of surgery in conservatively treated patients with scoliosis. Pediatric Rehabilitation 2003, 6:111-8.

112. Edelmann P: Brace treatment in idiopathic scoliosis. Acta Orthop Belg 1992, 58(Suppl 1):85-90.

113. Negrini S, Atanasio S, Zaina F, Romano M, Parzini S, Negrini A: End-growth results of bracing and exercises for adolescent idiopathic scoliosis. Prospective worst-case analysis. Studies in Health Technology and Informatics 2008, 135:395-408.

114. Coillard C, Leroux MA, Zabjek KF, Rivard CH: SpineCor-a non-rigid brace for the treatment of idiopathic scoliosis: post-treatment results. Eur Spine J 2003, 12(2):141-8, Epub 2002 Nov 7.

115. Szwed A, Kołban M, Jałoszewski M: Results of SpineCor dynamic bracing for idiopathic scoliosis. Ortop Traumatol Rehabil 2009, 11(5):427-32.

116. Wong MS, Cheng JC, Lam TP, Ng BK, Sin SW, Lee-Shum SL, Chow DH, Tam SY: The effect of rigid versus flexible spinal orthosis on the clinical efficacy and acceptance of the patients with adolescent idiopathic scoliosis. Spine (Phila Pa 1976) 2008, 33(12):1360-5

117. Weiss HR, Weiss GM: Brace treatment during pubertal growth spurt in girls with idiopathic scoliosis (IS): a prospective trial comparing two different concepts. Pediatr Rehabil 2005, 8(3):199-206.

118. Dolan LA, Donnelly MJ, Spratt KF, Weinstein SL: Professional opinion concerning the effectiveness of bracing relative to observation in adolescent idiopathic scoliosis. J Pediatr Orthop 2007, 27(3):270-6.

119. Weiss HR, Bess S, Wong MS, Patel V, Goodall D, Burger E: Adolescent idiopathic scoliosis - to operate or not? A debate article. Patient Saf Surg 2008, 2:25

120. Dolan LA, Weinstein SL: Surgical rates after observation and bracing for adolescent idiopathic scoliosis: an evidence-based review. Spine (Phila Pa 1976) 2007, 32(19 Suppl):S91-S100.

121. Thompson GH, Richards BS lii: Inclusion and assessment criteria for conservative scoliosis treatment. Stud Health Technol Inform 2008, 135:157-63.

122. Weiss HR, Werkmann M, Stephan C: Brace related stress in scoliosis patients - Comparison of different concepts of bracing. Scoliosis 2007, 2:10.

123. Kessler J: Efficacy of a new computer-aided design/computer-aided manufacture orthosis in the treatment of adolescent idiopathic scoliosis. J Pediatr Orthop B 2008, 17(4):207-11.

124. Weiss HR, Werkmann M, Stephan C: Correction effects of the ScoliOlogiC "Chêneau light" brace in patients with scoliosis. Scoliosis 2010, 2:02.

125. Weiss HR: "Brace Technology" Thematic Series - The Gensingen brace (TM) in the treatment of scoliosis. Scoliosis 2010, 5:22.

126. Weiss HR, Werkmann M: "Brace Technology" Thematic Series - The ScoliOlogiC(R) Cheneau light(TM) brace in the treatment of scoliosis. Scoliosis 2010, 5:19.

127. Vasiliadis ES, Grivas TB, Kaspiris A: Historical overview of spinal deformities in ancient Greece. Scoliosis 2009, 4:6, (25 February 2009).

128. Weiss HR: Befundgerechte Physiotherapie bei Skoliose. 3 edition. Pflaum, Munich; 2011.

129. Lehnert-Schroth C: The Schroth Scoliosis Three-Dimensional Treatment Books on demand, Norderstedt; 2007, (ISBN 978-3-8334-8138-3).

130. Yilmaz H, Kozikoglu L: Inpatient rehabilitation - A systematic Pub Med review. The Internet Journal of Rehabilitation 2010, 1:1 [http://www.ispub. com/journal/the internet_journal_of rehabilitation/ volume_1_number_1_73/article/inpatient-rehabilitation-a-systematic-pubmed-review.html].

131. Weiss HR, Hollaender M, Klein R: ADL based scoliosis rehabilitation-the key to an improvement of time-efficiency? Stud Health Technol Inform 2006, 123:594-598

132. Weiss HR, Klein R: Improving excellence in scoliosis rehabilitation: a controlled study of matched pairs. Pediatr Rehabil 2006, 9:3, 190-200 Jul/ Sep.

133. Weiss HR, Seibel S: Scoliosis short-term rehabilitation (SSTR) - a pilot investigation. The Internet Journal of Rehabilitation 2010, 1:1 [http://www. ispub.com/journal/the_internet_journal_of_rehabilitation/ volume_1_number_1_73/article/scoliosis-short-term-rehabilitation-sstr-apilot-investigation.html].

134. Weiss HR: Skolioserehabilitation. Qualitätssicherung und Management Georg Thieme Verlag, Stuttgart; 2000. 
135. Otman S, Kose N, Yakut Y: The efficacy of Schroth s 3-dimensional exercise therapy in the treatment of adolescent idiopathic scoliosis in Turkey. Saudi Med J 2005, 26:1429-1435.

136. Freidel K, Petermann F, Reichel D, Steiner A, Warschburger P, Weiss HR: Quality of life in women with idiopathic scoliosis. Spine 2002, 15:87-91.

137. Landauer F, Hofstädter Th: Proportion of correction and compliance to determine success in brace treatment. Scoliosis 2007, 2(Suppl 1):S13,

138. Weiss HR: Rehabilitation of scoliosis patients with pain after surgery. Stud Health Technol Inform 2002, 88:250-253.

139. Weiss HR, Werkmann M: Unspecific chronic low back pain - a simple functional classification tested in a case series of patients with spinal deformities. Scoliosis 2009, 4:04.

140. Weiss HR, Werkmann M: Treatment of chronic low back pain in patients with spinal deformities using a sagittal re-alignment brace. Scoliosis 2009, 4:07.

141. Weiss HR: Die Konservative Skoliosebehandlung. Lichtblick 2010, , 3: 3-12.

142. Weiss HR, Goodall D: Total case management - the key to really etimate cost effectiveness in certain orthopedic conditions in Germanys health system. The Internet Journal of Healthcare Administration, 2010, 7:1.

143. Medtronic to Pay $\$ 1.35$ Billion to Inventor. [http://www.nytimes.com/ 2005/04/23/business/23medronic.html?_r=2\&ex = 1271908800\&en= f2b6a791 c937140a\&ei=5090\&partner=rssuserland\&emc=rss].

144. Scoliosis short-term rehabilitation (SSTR). [http://www.youtube.com/ watch?v=eHsCSL7|EaU].

145. Scoliosis 'Best Practice' course in Gensingen (in Russian). [http://www. youtube.com/watch?v=Ke88YIDrlfg].

146. New Power Schroth 2010. [http://www.youtube.com/watch? $v=n P W v a p T L 1 n E]$.

147. 'Best Practice' Korean Scoliosis course (A-Level) - first part. [http://www. youtube.com/watch? $\mathrm{v}=$ fYu_Mw2dlQk].

148. Best Practice' Korean Scoliosis course (A-Level) - second part. [http:// www.youtube.com/watch?v=4HgPVq92vlo].

doi:10.1186/1748-7161-5-28

Cite this article as: Weiss: Spinal deformities rehabilitation - state of the art review. Scoliosis 2010 5:28.

\section{Submit your next manuscript to BioMed Central and take full advantage of:}

- Convenient online submission

- Thorough peer review

- No space constraints or color figure charges

- Immediate publication on acceptance

- Inclusion in PubMed, CAS, Scopus and Google Scholar

- Research which is freely available for redistribution

Submit your manuscript at www.biomedcentral.com/submit 